\title{
Brain magnetic resonance imaging abnormalities after the Norwood procedure using regional cerebral perfusion
}

\author{
Catherine L. Dent, MD, a James P. Spaeth, MD, ${ }^{\text {b }}$ Blaise V. Jones, MD, ${ }^{e}$ Steven M. Schwartz, MD, ${ }^{a}$ \\ Tracy A. Glauser, MD, ${ }^{b}$ Barbara Hallinan, MD, Jeffrey M. Pearl, MD, ${ }^{d}$ Philip R. Khoury, MS, ${ }^{a, c}$ and C. Dean Kurth, MD
}

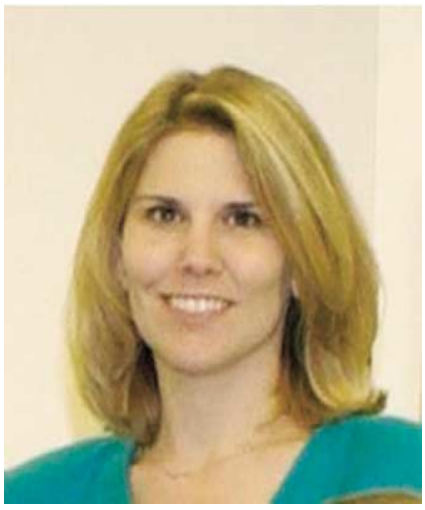

Dr Dent
From the Departments of Pediatrics (Divisions of Cardiology, ${ }^{a}$ Neurology, ${ }^{\mathrm{b}}$ and Epidemiology/Biostatistics), ${ }^{\mathrm{c}}$ Surgery (Division of Cardiothoracic Surgery), ${ }^{\mathrm{d}}$ Radiology, ${ }^{\mathrm{e}}$ and Anesthesiology, ${ }^{\mathrm{f}}$ Cincinnati Children's Hospital Medical Center and the University of Cincinnati College of Medicine, Cincinnati, Ohio.

Received for publication June 14, 2005; revisions received July 19, 2005; accepted for publication Aug 29, 2005.

Address for reprints: Catherine Dent, MD, Cincinnati Children's Hospital Medical Center, 3333 Burnet Ave, MLC 2003, Cincinnati, OH 45229-3039 (E-mail: catherine. dent@cchmc.org).

J Thorac Cardiovasc Surg 2006;131:190-7

$0022-5223 / \$ 32.00$

Copyright ( $\odot 2006$ by The American Association for Thoracic Surgery

doi:10.1016/j.jtcvs.2005.10.003
Objectives: Neurologic deficits are common after the Norwood procedure for hypoplastic left heart syndrome. Because of the association of deep hypothermic circulatory arrest with adverse neurologic outcome, regional low-flow cerebral perfusion has been used to limit the period of intraoperative brain ischemia. To evaluate the impact of this technique on brain ischemia, we performed serial brain magnetic resonance imaging in a cohort of infants before and after the Norwood operation using regional cerebral perfusion.

Methods: Twenty-two term neonates with hypoplastic left heart syndrome were studied with brain magnetic resonance imaging before and at a median of 9.5 days after the Norwood operation. Results were compared with preoperative, intraoperative, and postoperative risk factors to identify predictors of neurologic injury.

Results: Preoperative magnetic resonance imaging $(\mathrm{n}=22)$ demonstrated ischemic lesions in $23 \%$ of patients. Postoperative magnetic resonance imaging $(n=15)$ demonstrated new or worsened ischemic lesions in $73 \%$ of patients, with periventricular leukomalacia and focal ischemic lesions occurring most commonly. Prolonged low postoperative cerebral oximetry ( $<45 \%$ for $>180$ minutes) was associated with the development of new or worsened ischemia on postoperative magnetic resonance imaging $(P=.029)$.

Conclusions: Ischemic lesions occur commonly in neonates with hypoplastic left heart syndrome before surgery. Despite the adoption of regional cerebral perfusion, postoperative cerebral ischemic lesions are frequent, occurring in the majority of infants after the Norwood operation. Long-term follow-up is necessary to assess the functional impact of these lesions.

$\mathrm{N}$ eurologic and developmental abnormalities are common in children with hypoplastic left heart syndrome (HLHS) after the Norwood procedure. ${ }^{1-5}$ Although the cause of brain injury in these infants is likely multifactorial with contributions from preoperative, intraoperative, and postoperative events, the use of deep hypothermic circulatory arrest (DHCA) seems to play a role in poor neurologic and developmental outcome. ${ }^{6-10}$ Ischemic brain lesions have been documented on pathologic brain specimens ${ }^{11}$ and on magnetic resonance imaging (MRI) ${ }^{12}$ in neonates after surgical palliation in which DHCA is used.

Because of these concerns, many centers have adopted the technique of regional low-flow cerebral perfusion (RLFP) during the aortic arch reconstruction in lieu of DHCA. RLFP decreases the period of cerebral ischemia by limiting decreases in cerebral blood volume and oxygen saturation. ${ }^{13}$ Although RLFP has been associated with better neurologic outcome in animal models, ${ }^{14}$ such studies have not been performed in humans. In the present study, we compare preoperative and postop- 

Abbreviations and Acronyms
BT = Blalock-Taussig
$\mathrm{CICU}=$ cardiac intensive care unit
$\mathrm{CPB}=$ cardiopulmonary bypass
$\mathrm{DHCA}=$ deep hypothermic circulatory arrest
EEG = electroencephalogram
HLHS = hypoplastic left heart syndrome
MRI = magnetic resonance imaging
PVL = periventricular leukomalacia
RLFP = regional low-flow cerebral perfusion
$\mathrm{rSO}_{2}=$ regional oxygen saturation
$\mathrm{SaO}_{2}=$ arterial oxygen saturation
$\mathrm{SvO}_{2}=$ venous oxygen saturation

erative brain MRI findings in neonates undergoing the Norwood procedure using RLFP.

\section{Patients and Methods}

With institutional review board approval and informed consent, all infants with HLHS or its variants who were admitted to the cardiac intensive care unit (CICU) at Cincinnati Children's Hospital Medical Center between September 2003 and March 2005 were evaluated for study inclusion. Inclusion criteria included term gestational age ( $\geq 36$ weeks) and an intention to undergo surgical intervention (Norwood operation with aortic arch reconstruction) using RLFP. Infants were excluded if they had a (1) history of birth asphyxia (5-minute Apgar score <5), (2) genetic anomaly associated with neurodevelopmental abnormalities, or (3) preoperative cardiac arrest.

MRI scans of the brain were performed preoperatively (day of surgery) and in the early postoperative period. The scans were performed on a Signa LX 1.5-T scanner (GE Medical, Milwaukee, Wis). The following sequences were performed: (1) sagittal T1weighted spin-echo images, (2) axial T1-weighted inversionrecovery images, (3) axial and coronal T2-weighted fast spin-echo images, (4) axial diffusion-weighted images, and (5) short echo proton magnetic resonance spectroscopy in the basal ganglia. All MRI scans were reviewed by a single neuroradiologist blinded to the subjects' clinical status. MRI scans were reviewed for congenital and acquired lesions including general or focal atrophy, periventricular leukomalacia (PVL), cerebral edema, delayed myelination, intraparenchymal hemorrhage, intraventricular hemorrhage, and infarct. All lesions were classified as mild, moderate, or severe. PVL, infarction, and intraparenchymal hemorrhage were considered to represent ischemia.

\section{Clinical Management}

Preoperative clinical management was provided in the CICU. Infants were maintained on a continuous prostaglandin infusion. Pulmonary overcirculation was managed with administration of subambient oxygen $\left(\mathrm{FIO}_{2} 0.17-0.20\right)$ or addition of inhaled $\mathrm{CO}_{2}$. Inotropic medication was administered at the discretion of the attending physician. As an assessment of overall status, a preoperative inotropic score was calculated as the sum of all inotrope doses, correcting for potency. ${ }^{15,16}$ Preoperative neurologic evaluation included an electroencephalogram (EEG) and examination by a pediatric neurologist directed at level of consciousness, motor tone, response to stimuli, and deep tendon reflexes. Regional cerebral oxygen saturation $\left(\mathrm{rSO}_{2}\right)$ was monitored continuously with near-infrared spectroscopy (Somanetics INVOS 5100A, Troy, Mich) with the probe placed on the right side of the patient's forehead. Monitoring commenced 12 hours before surgery. Data were recorded at 1-minute intervals. An $\mathrm{rSo}_{2}$ value less than $45 \%$ was considered to represent cerebral desaturation. Cumulative time spent with $\mathrm{rSO}_{2}$ less than $45 \%$ was recorded. Management was not altered on the basis of cerebral oximetry readings.

For the preoperative MRI, anesthesia was induced with fentanyl $(5 \mu \mathrm{g} / \mathrm{kg})$, midazolam $(0.1 \mathrm{mg} / \mathrm{kg})$, and vecuronium $(0.2 \mathrm{mg} / \mathrm{kg})$. In patients not already mechanically ventilated, nasotracheal intubation was performed. Patients were monitored during the MRI with continuous pulse oximetry, capnography, electrocardiography, and blood pressure measurements. After the MRI, patients were transported to the operating suite for cardiac surgery. Surgical repair consisted of aortic arch reconstruction, ascending aorta-pulmonary artery anastomosis, and creation of an unrestrictive atrial septal communication. Pulmonary blood flow was provided by either a systemic-pulmonary artery shunt or a right ventricle-pulmonary artery conduit.

Cardiopulmonary bypass (CPB) and surgical management followed our usual institutional practice. Whole blood was added to the primer to yield a goal hematocrit of $28 \%$ to $30 \%$ during CPB. Arterial blood gas-pH management followed the $\alpha$-stat strategy on CPB initiation with switch to pH-stat strategy during cooling. The $\alpha$-stat strategy was resumed during rewarming. All patients were cooled to deep hypothermia $\left(18^{\circ} \mathrm{C}\right)$. During reconstruction of the aortic arch, continuous RLFP was provided through the innominate shunt at $30 \mathrm{~mL} \cdot \mathrm{kg} \cdot \mathrm{min}$. Before separation from CPB, patients received a loading dose of milrinone $(37.5 \mu \mathrm{g} / \mathrm{kg})$. Dopamine and epinephrine infusions were instituted and titrated to achieve adequate blood pressure and systemic vascular resistance.

Postoperative management was provided in the CICU. Inotropic medication was adjusted at the discretion of the attending physician. Sodium nitroprusside was added as tolerated for afterload reduction and to improve cardiac output. Management targets included mean arterial pressure of $45 \mathrm{~mm} \mathrm{Hg}$ or greater, mixed venous oxygen saturation $\left(\mathrm{SvO}_{2}\right) 50 \%$ or greater, arterial oxygen saturation $\left(\mathrm{SaO}_{2}\right)$ $70 \%$ or greater, and hematocrit greater than $40 \%$. Blood for $\mathrm{SvO}_{2}$ measurement was sampled from a catheter placed intraoperatively in the superior vena cava. $\mathrm{SvO}_{2}$ was measured on admission and every 4 hours. Cerebral $\mathrm{rSo}_{2}$ mon- 
TABLE 1. Patient demographics and cardiac diagnoses

$\begin{array}{lr}\text { Cohort size } & 22 \\ \text { Sex } & 15 \\ \quad \text { Male } & 7 \\ \text { Female } & 3 \\ \text { Race } & 19 \\ \quad \text { African American } & \\ \quad \text { White } & 18 \\ \text { Cardiac diagnoses } & 1 \\ \quad \text { HLHS } & 1 \\ \text { DORV/mitral atresia/aortic arch hypoplasia } & 1 \\ \quad \text { Heterotaxy/DILV/aortic arch hypoplasia } & 1 \\ \text { TA/TGA/aortic arch hypoplasia } & \\ \text { DORV/LV hypoplasia/aortic arch hypoplasia } & \\ \text { Birth weight (kg) 2.94 (2.1-3.96) } & \\ \text { Birth head circumference (cm) 33.5 (32.5-37.0) } & \\ \text { Gestational age (wk) 39 (36-41) } & \\ \text { Size for gestational age } & 21 \\ \quad \text { AGA } & 1 \\ \text { SGA } & \end{array}$

5-minute Apgar score 9 (8-9).

$H L H S$, Hypoplastic left heart syndrome; DORV, double outlet right ventricle; $D I L V$, double inlet left ventricle; $T A$, tricuspid atresia; $T G A$, transposition of the great arteries; $L V$, left ventricle; $A G A$, appropriate for gestational age; $S G A$, small for gestational age. Values are expressed as median and range where appropriate.

itoring continued for 48 hours after surgery. Postoperative inotrope scores were calculated every 6 hours.

The postoperative MRI was performed when the patients were deemed suitable for transport, generally between 5 and 14 days after surgery. Sedation was provided with oral pentobarbital $(5 \mathrm{mg} / \mathrm{kg})$ in spontaneously breathing patients and with inhaled anesthesia in intubated patients. Patients were monitored in similar fashion as with the preoperative scan. Postoperative EEG and neurologic examination by a pediatric neurologist were performed when the patient was no longer receiving sedation.

\section{Data Collection and Statistical Analysis}

Primary outcome measures were (1) ischemia on preoperative MRI and (2) development of new or worsened parenchymal lesions on postoperative MRI when compared with the preoperative study. Data collected preoperatively included patient demographics, birth history, Apgar scores, birth weight and head circumference, indirect measures of cardiac output (acid-base status [pH and base deficit], serum lactate, mean arterial pressure, $\mathrm{SaO}_{2}$ ), inotropic score, and $\mathrm{rSO}_{2}$. Operative events (including type of shunt placed for pulmonary blood flow, duration of CPB, RLFP, and DHCA) and intraoperative variables (acid-base status, serum lactate, hematocrit, and $\mathrm{rSO}_{2}$ ) were included in analysis. Postoperative variables analyzed included acid-base status $\mathrm{pH}$ and base deficit), lactate, mean arterial pressure, diastolic arterial pressure, urine output, inotropic scores, $\mathrm{SaO}_{2}, \mathrm{SvO}_{2}$, and
TABLE 2. Patient preoperative variables

\begin{tabular}{lccc}
\hline Variable & Mean \pm SD & Median & Range \\
\hline Preop inotrope score & $3.6 \pm 4.0$ & 5 & $0-15$ \\
Preop hematocrit (\%) & $41.6 \pm 3.7$ & 41.0 & $33.4-48.2$ \\
Average preop $\mathrm{SaO}_{2}(\%)$ & $89.4 \pm 6.3$ & 90.3 & $88.5-94.0$ \\
Average preop $\mathrm{rSO}_{2}(\%)$ & $60.7 \pm 8.2$ & 59.0 & $44-79$ \\
Lowest preop pH & $7.31 \pm 0.06$ & 7.30 & $7.20-7.43$ \\
Largest preop base deficit & $4.2 \pm 1.9$ & 4 & $1-7.5$ \\
Highest serum lactate (mmol/L) & $2.9 \pm 1.2$ & 2.7 & $1.0-5.6$ \\
\hline
\end{tabular}

$\mathrm{SaO}_{2}$, Arterial oxygen saturation; $r \mathrm{SO}_{2}$, regional oxygen saturation.

$\mathrm{rSO}_{2}$. Cerebral desaturation was assessed both as a continuous variable (cumulative minutes with $\mathrm{rSO}_{2}<45 \%$ ) and a categorical variable ( $>$ or $<180$ cumulative minutes of cerebral desaturation).

Distributions of variables were examined for normality, and appropriate adjustments were performed by using variance stabilizing transformations or nonparametric analyses, when necessary. Associations between the outcome variables and various risk factors were analyzed using Fisher exact tests for categorical outcome and risk factor variables, Student $t$ tests and logistic regression for binary outcomes, and linear regression for continuous variables. Analysis was performed with SAS statistical software (SAS Institute, Cary, NC).

\section{Results}

Twenty-two of 30 eligible neonates were enrolled. Table 1 details patient demographic information. All infants were of term gestation and had normal 5-minute Apgar scores. One infant was small for gestational age. All infants had normal head circumference (between the 5th and 95th percentiles). The male predominance $(68 \%)$ in our study is compatible with a known higher occurrence of HLHS in boys. ${ }^{17}$ Prenatal diagnosis of congenital heart disease had been made in $17(77 \%)$ of the 22 patients.

Table 2 summarizes patient preoperative status. Subambient oxygen $\left(\mathrm{FIO}_{2} 0.17-0.20\right)$ was used to manage preoperative pulmonary overcirculation in 12 of the 22 patients. One patient received inhaled $\mathrm{CO}_{2}$. Nine of the 22 patients were mechanically ventilated before the day of surgery. Twelve patients received inotropic medication before surgery; 11 of the 12 patients received a single inotropic medication, and 1 patient received 2 inotropic medications. Average inotrope score before surgery was $3.6 \pm 4.0$. Average preoperative $\mathrm{rSO}_{2}$ was $60.7 \% \pm 8.2 \%$, and $\mathrm{SaO}_{2}$ was $89.4 \% \pm$ $6.3 \%$. Significant low cardiac output was not observed in any patient before surgery.

Patients underwent the Norwood procedure at a median age of 4 days (range 1-8 days). The procedure was accomplished using a brief period of DHCA followed by RLFP in 21 of the 22 patients. In 1 patient, surgery was accomplished 
TABLE 3. Summary of preoperative studies

\begin{tabular}{|c|c|c|c|c|c|}
\hline $\begin{array}{l}\text { Patient } \\
\text { No. }\end{array}$ & $\begin{array}{l}\text { Preop neurologic } \\
\text { examination }\end{array}$ & $\begin{array}{l}\text { Preop } \\
\text { EEG }\end{array}$ & Preop MRI & $\begin{array}{l}\text { Preop } \\
\text { MRS }\end{array}$ & $\begin{array}{c}\text { Preop minutes } \\
\mathrm{rSO}_{2}<45 \%\end{array}$ \\
\hline 1 & Normal & ND & No ischemia; $\uparrow \mathrm{T} 1$ basal ganglia/thalamus & Normal & 0 \\
\hline 2 & ND & ND & No ischemia; $\uparrow \mathrm{T} 1$ basal ganglia/thalamus & ND & 0 \\
\hline 3 & ND & Normal & No ischemia; & ND & 0 \\
\hline 4 & $\downarrow$ LOC & Normal & $\begin{array}{l}\text { No ischemia; small extra-axial } \\
\text { hemorrhage occipital lobes }\end{array}$ & Normal & 0 \\
\hline 5 & $\downarrow$ LOC & Normal & No ischemia; $\uparrow \mathrm{T} 1$ basal ganglia/thalamus & Normal & 0 \\
\hline 6 & $\downarrow$ LOC & ND & No ischemia & Normal & 0 \\
\hline 7 & Normal & Normal & No ischemia & Normal & 0 \\
\hline 8 & Normal & Normal & No ischemia & Normal & 0 \\
\hline 9 & ND & ND & No ischemia & Normal & 0 \\
\hline 10 & $\downarrow$ LOC & Normal & No ischemia & Normal & 101 \\
\hline 11 & $\downarrow$ LOC & Normal & No ischemia; $\uparrow \mathrm{T} 1$ basal ganglia/thalamus & Normal & 23 \\
\hline 12 & Normal & Normal & No ischemia & Normal & 0 \\
\hline 13 & Normal & ND & No ischemia & Normal & 392 \\
\hline 14 & ND & ND & No ischemia & Normal & 18 \\
\hline 15 & Normal & Abnormal & No ischemia; $\uparrow \mathrm{T} 1$ basal ganglia/thalamus & Normal & 0 \\
\hline 16 & Normal & Abnormal & Small ischemic lesion L-frontal lobe & Normal & 0 \\
\hline 17 & Normal & Normal & $\begin{array}{l}\text { Small ischemic lesion R-frontal lobe; } \uparrow \mathrm{T} 1 \\
\text { basal ganglia/thalamus }\end{array}$ & Normal & 0 \\
\hline 18 & Normal & Normal & No ischemia & Normal & 0 \\
\hline 19 & Normal & Normal & Moderate PVL & Normal & 0 \\
\hline 20 & Normal & ND & $\begin{array}{l}\text { Small ischemic lesion L-frontal lobe; small } \\
\text { extra-axial hemorrhage posterior fossa; } \\
\uparrow \mathrm{T} 1 \text { basal ganglia/thalamus }\end{array}$ & Normal & 0 \\
\hline 21 & $\uparrow$ muscle tone & Abnormal & $\begin{array}{l}\text { Small ischemic lesion L-frontal lobe; } \uparrow \mathrm{T} 1 \\
\text { basal ganglia/thalamus }\end{array}$ & Normal & 0 \\
\hline 22 & ND & Normal & Normal & Normal & 0 \\
\hline
\end{tabular}

LOC, Level of consciousness; PVL, periventricular leukomalacia; DTR, deep tendon reflex; $\uparrow T 1$ basal ganglia/thalamus, increased T1 signal in basal ganglia and thalamus of unclear significance; $N D$, not done; $r \mathrm{SO}_{2}$, regional oxygen saturation; $M R I$, magnetic resonance imaging; $E E G$, electroencephalogram; $M R S$, magnetic resonance spectroscopy.

with DHCA alone (rather than RLFP) because of complex strap vessel anatomy (cervical aortic arch with aberrant right subclavian artery and small right carotid artery). This patient was subsequently excluded from postoperative results and analysis. In the 21 patients with RLFP, the mean duration was $186.4 \pm 46.5$ minutes for $\mathrm{CPB}, 5.5 \pm 5.7$ minutes for DHCA, and $83.4 \pm 15.2$ minutes for RLFP. Fifteen of the 21 patients had a modified Blalock-Taussig (BT) shunt $(3.0-3.5 \mathrm{~mm})$ placed, and 6 of the 21 patients had a 5-mm right ventricle-pulmonary artery conduit performed.

\section{Neurologic Evaluation and Magnetic Resonance Imaging Results \\ Preoperative Studies}

Table 3 summarizes preoperative results. Preoperative neurologic examination was performed in 17 of the 22 patients. Eleven patients had normal examination results, 5 patients had diminished levels of consciousness because of sedative medications but otherwise had normal examination results, and 1 patient had increased muscle tone. Of the 15 patients with a preoperative EEG, 12 infants $(80 \%)$ had normal EEG pattern and 3 patients (20\%) had mild diffuse slowing. These 3 patients all had normal neurologic examination results and were not receiving sedative medication. No seizures were observed clinically or by EEG before surgery. Preoperative MRI was performed on the day of surgery in all 22 patients. No congenital structural abnormalities were identified in any patient. Ischemic lesions were seen in 5 of 22 patients $(23 \%)$. One infant had multifocal diffusion abnormalities in the parietal white matter consistent with mild PVL, 1 patient had focal infarction in the right frontal lobe, and 3 patients had focal ischemic lesions in the left frontal lobe. Extra-axial hemorrhage was identified in 2 patients who had bilateral small hemorrhagic collections in the posterior cerebral and occipital regions. In 8 of the 22 patients (36\%), 5 of whom had otherwise normal study results, mild increases in $\mathrm{T} 1$ signal of unclear significance occurred in the basal ganglia/thalamic region. Ten patients had completely normal study results. 
TABLE 4. Summary of postoperative studies

\begin{tabular}{|c|c|c|c|c|c|c|}
\hline $\begin{array}{l}\text { Patient } \\
\text { No. }\end{array}$ & $\begin{array}{l}\text { Type of } \\
\text { shunt }\end{array}$ & $\begin{array}{c}\text { Postop neurologic } \\
\text { examination }\end{array}$ & Postop EEG & Postop MRI & Postop MRS & $\begin{array}{c}\text { Postop minutes } \\
\mathrm{rSO}_{2}<45 \%\end{array}$ \\
\hline 1 & BTS & $\begin{array}{l}\text { Normal; clinical } \\
\text { seizures }\end{array}$ & Abnormal (seizures) & $\begin{array}{l}\text { Moderate PVL; moderate extra- } \\
\text { axial blood; mild IVH }\end{array}$ & $\uparrow$ Lactate & 224 \\
\hline 2 & RV-PA & $\uparrow \mathrm{DTR}$ & Normal & Mild atrophy; no ischemia & Normal & 58 \\
\hline 3 & BTS & Normal & Normal & $\begin{array}{l}\text { Small hemorrhagic-ischemic lesion } \\
\text { R-frontal lobe }\end{array}$ & Normal & 298 \\
\hline $4^{*}$ & RV-PA & Normal & Normal & Excluded & Normal & 1163 \\
\hline 5 & BTS & Normal & Normal & $\begin{array}{l}\text { Small hemorrhagic-ischemic lesion } \\
\text { R-frontal lobe, mild atrophy }\end{array}$ & Normal & 13 \\
\hline 6 & BTS & $\uparrow \mathrm{DTR}$ & Normal & $\begin{array}{l}\text { Mild PVL; mild extra-axial blood, } \\
\text { mild IVH }\end{array}$ & Normal & 359 \\
\hline 7 & BTS & Normal & Normal & Normal & Normal & 170 \\
\hline 8 & BTS & Normal & Normal & ND (pacemaker) & ND & 385 \\
\hline 9 & RV-PA & ND & ND & ND (early death) & ND & 562 \\
\hline 10 & BTS & ND & ND & ND (early death) & ND & ND \\
\hline 11 & BTS & Normal & Normal & Mild PVL & Normal & 222 \\
\hline 12 & BTS & Normal & Normal & Mild atrophy; mild IVH; no ischemia & Normal & 325 \\
\hline 13 & BTS & ND & ND & ND (early death) & ND & 894 \\
\hline 14 & BTS & ND & ND & ND (early death) & ND & ND \\
\hline 15 & BTS & Normal & Normal & Normal & Normal & 56 \\
\hline 16 & RV-PA & Normal & Normal & $\begin{array}{l}\text { Mild PVL; small ischemic lesion } \\
\text { L-frontal lobe; mild IVH }\end{array}$ & Normal & 367 \\
\hline 17 & RV-PA & Normal & Normal & $\begin{array}{l}\text { Moderate PVL; moderate } \\
\text { hemorrhagic-ischemic lesion L- } \\
\text { frontal lobe; mild IVH; mild extra- } \\
\text { axial blood }\end{array}$ & $\uparrow$ Lactate & 537 \\
\hline 18 & RV-PA & Normal & Normal & Mild PVL; mild IVH & Normal & 458 \\
\hline 19 & BTS & Normal & Normal & $\begin{array}{l}\text { Moderate PVL; small R-cerebellar } \\
\text { infarction; mild IVH }\end{array}$ & Normal & 0 \\
\hline 20 & BTS & Normal & Normal & $\begin{array}{l}\text { Mild PVL; small ischemic lesion } \\
\text { L-frontal lobe; mild extra-axial } \\
\text { blood }\end{array}$ & Normal & 749 \\
\hline 21 & BTS & $\begin{array}{l}\uparrow \mathrm{DTR} \uparrow \text { muscle } \\
\text { tone; clinical } \\
\text { seizures }\end{array}$ & Abnormal (seizures) & $\begin{array}{l}\text { Moderate L-frontal hemorrhagic- } \\
\text { ischemic lesion; large L-subdural } \\
\text { hemorrhage }\end{array}$ & $\uparrow$ Lactate & 228 \\
\hline 22 & BTS & ND & ND & ND (early death) & ND & 27 \\
\hline
\end{tabular}

BTS, Blalock-Taussig shunt; $R V$ - $P A$, right ventricle-to-pulmonary artery conduit; $D T R$, deep tendon reflexes; $P V L$, periventricular leukomalacia; $I V H$, intraventricular hemorrhage; $N D$, not done; $\mathrm{rSO}_{2}$, regional oxygen saturation; $M R I$, magnetic resonance imaging; $E E G$, electroencephalogram; $M R S$, magnetic resonance spectroscopy. *Surgery performed with DHCA; patient excluded from MRI results and risk factor analysis.

Magnetic resonance spectroscopy was performed in 20 of the 22 patients, including the 5 with ischemic lesions, and demonstrated normal patterns without lactate elevation in all patients.

Cerebral oximetry was performed in all 22 patients for 12 hours before surgery. In 18 of the 22 patients, $\mathrm{rSO}_{2}$ remained more than $45 \%$ throughout the preoperative monitoring period. Two patients spent more than 60 cumulative minutes with $\mathrm{rSO}_{2}$ less than $45 \%$. Both of these patients had normal preoperative MRI study results but died in the early postoperative period and did not have follow-up MRI studies performed.

\section{Postoperative Studies}

Table 4 summarizes postoperative study results. Of the 21 patients who underwent surgery using RLFP, postoperative MRI was performed in 15 patients. Five patients died early after surgery, and MRI was deferred in 1 patient because of the need for cardiac pacing. The median duration between surgery and postoperative MRI was 9.5 days (range 4-112 days). Two patients had follow-up MRI performed more than 3 weeks after surgery because of clinical instability.

Postoperative neurologic examination was performed in 17 of the 22 patients. One patient (with significant ischemia and subdural hemorrhage on MRI) demonstrated increased 


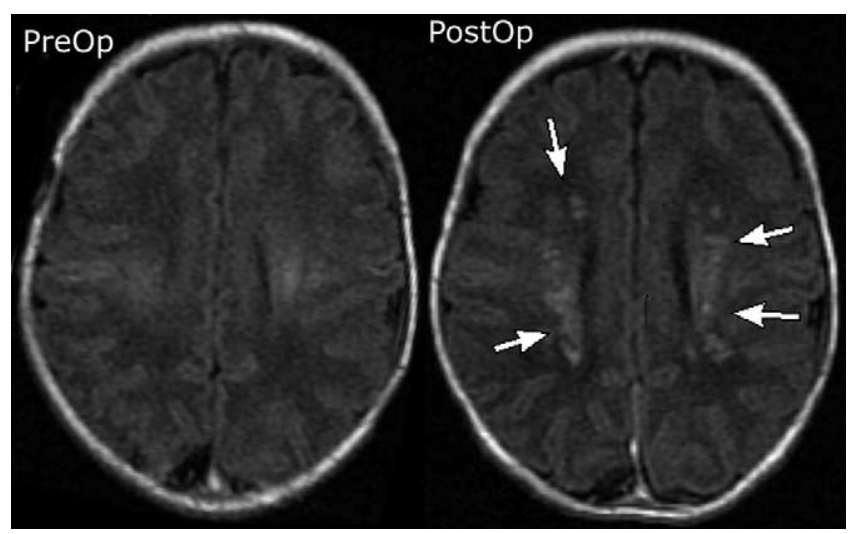

Figure 1. Axial T-1 inversion recovery images on a patient before (left) and 7 days after (right) surgery. Preoperative magnetic resonance imaging (MRI) showed normal findings. Multiple foci of hemorrhagic staining within the periventricular white matter (arrows) developed in this infant, characteristic of ischemia from hypoperfusion.

tone and deep tendon reflexes, and 2 patients (1 with mild PVL on MRI and 1 with normal MRI findings) had increased deep tendon reflexes. All other examination results were considered normal. Postoperative EEG was performed in 17 patients; 15 of the patients had normal results. Two patients (both with clinical seizures and ischemia on postoperative MRI) had focal seizures on EEG. Clinical seizures were not observed in any other patient.

New or worsened ischemic lesions were observed in 11 (73\%) of 15 patients. These lesions included PVL in 7 patients (47\%) and focal ischemic or hemorrhagic-ischemic lesions in 8 patients $(53 \%)$. The PVL occurred primarily in the frontoparietal region and occurred bilaterally in 6 of the 7 patients (Figure 1). All patients with preoperative ischemia had new or worsened lesions on postoperative study. Mild extra-axial (subdural or choroid plexus) or intraventricular hemorrhage not requiring intervention was observed in 7 patients $(47 \%)$. One patient had significant hemorrhage into an area of ischemia in the left frontal area (seen preoperatively), which was surgically drained (Figure 2). Magnetic resonance spectroscopy demonstrated lactate elevation in 3 of the 15 patients, all with ischemic lesions on MRI. Eight of 11 patients with conventional BT shunt (73\%) and 3 of 4 patients with right ventricle-pulmonary artery conduits $(75 \%)$ had new or worsened ischemia on postoperative MRI.

Postoperative cerebral oximetry was performed on 20 of the total cohort of patients and in all of the 15 patients with postoperative MRI studies. Two patients died before postoperative monitoring. Ten of the 15 patients with MRI studies and 14 of the 20 patients monitored had prolonged $(>180$ cumulative minutes) cerebral desaturation $\left(\mathrm{rSO}_{2}<45 \%\right)$ in the postoperative period. Nine of the 16 patients with modified BT

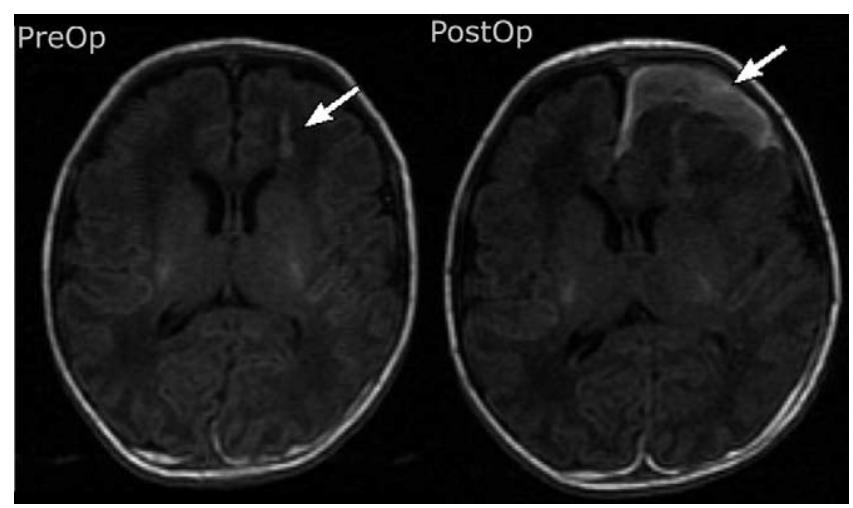

Figure 2. Axial T-1 inversion recovery images on a patient before (left) and 4 days after (right) surgery. Preoperative scan demonstrates increased signal intensity in the left frontal lobe (arrow) consistent with small focal area of hemorrhage. There are also small bilateral extra-axial subdural blood collections in the occipital regions. The postoperative scan demonstrates signal abnormalities consistent with new ischemia in the left frontal lobe and a large left frontal subdural/subarachnoid hemorrhage with mass effect (arrow). The extra-axial fluid collections have not changed.

shunts and 5 of the 6 patients with right ventricle-pulmonary artery conduits had prolonged cerebral desaturation.

\section{Risk Factor Analysis}

Analysis of preoperative variables demonstrated a significantly higher peak preoperative base deficit in patients with ischemic lesions on preoperative MRI, compared with those not showing ischemic lesions on preoperative MRI $(P=$ .024). No other preoperative variables, including other indirect measures of cardiac output, were associated with preoperative ischemia.

Analysis of risk factors for the presence of new or worsened area of ischemia on postoperative MRI demonstrated a significant association between prolonged postoperative low $\mathrm{rSO}_{2}\left(>180\right.$ cumulative minutes with $\mathrm{rSO}_{2}<$ $45 \%$ ) and the development of MRI lesions (Fisher exact test, $P=.029)$. Sensitivity and specificity were calculated at $82 \%$ and $75 \%$, respectively, with a positive predictive value of $90 \%$ and a negative predictive value of $60 \%$. The nadir of $\mathrm{rSO}_{2}$, indirect measures of cardiac output such as $\mathrm{SvO}_{2}$, and inotrope scores in the postoperative period were not related to the development of lesions. Similarly, intraoperative variables including type of pulmonary blood flow (BT shunt or right ventricle-pulmonary artery conduit) and durations of CPB and RLFP did not relate to the development of MRI ischemic lesions. Patients with evidence of preoperative ischemia were more likely to have new postoperative ischemia $(P=.08)$, but this did not reach statistical significance. 


\section{Discussion}

\section{Preoperative Findings}

This study confirms that MRI abnormalities are common in infants with HLHS before surgical intervention. Despite normal clinical examination and EEG findings, $23 \%$ of infants had evidence of ischemic lesions on MRI, primarily in the form of PVL or focal infarction. This incidence is similar to that seen in other populations with congenital heart disease. ${ }^{12,18}$

Risk factors for preoperative ischemia have not been well defined. In our study, although peak preoperative base deficit, one indicator of tissue perfusion, was associated with the presence of preoperative ischemia, other postnatal clinical indicators of overall cardiac output (eg, $\mathrm{pH}$ and serum lactate) were not associated with lesions on preoperative MRI. Our study also demonstrates that preoperative $\mathrm{rSO}_{2}$ is not associated with preoperative MRI ischemic lesions. A possible explanation for this finding is that cerebral ischemia occurred before the time period of near-infrared spectroscopy monitoring, either in utero or after birth but before the monitoring period. Although our near-infrared spectroscopy monitoring did not encompass the entire preoperative time period, no patient had a significant change in hemodynamics or $\mathrm{SaO}_{2}$ during the preoperative period, so the measurements obtained during our monitoring period are likely to be representative of the entire preoperative state. Nevertheless, because $\mathrm{rSO}_{2}$ measurements are being performed in a small (regional) area of the brain, they may not be a global representation of cerebral perfusion or may miss areas of regional ischemia, and may therefore be falsely reassuring. A recent study found that low cerebral blood flow is common in patients with congenital heart disease and is associated with MRI findings of PVL. ${ }^{18}$ There is also evidence that ischemia may occur in these infants in utero. Abnormalities in cerebral vascular blood flow dynamics have been found in fetuses with HLHS, similar to those seen with other forms of fetal hypoxia. ${ }^{19,20}$

In contrast with a previous study ${ }^{21}$ that demonstrated very low preoperative cerebral $\mathrm{rSO}_{2}$ in patients with HLHS, our study found cerebral desaturation to be relatively uncommon in our preoperative patients, with only 4 of the 22 patients having any preoperative $\mathrm{rSO}_{2}$ less than $45 \%$ and only 2 patients with more than 30 minutes with $\mathrm{rSO}_{2}$ less than $45 \%$. All 4 of these patients had normal preoperative MRI findings.

\section{Postoperative Findings}

Despite modification in surgical technique using RLFP, new or worsened ischemic brain lesions occurred in the majority (73\%) of our patients after the Norwood procedure, with an incidence similar to that seen with DHCA. ${ }^{12}$ Prolonged low $\mathrm{rSO}_{2}\left(>180\right.$ minutes with $\left.\mathrm{rSO}_{2} \leq 45 \%\right)$ was associated with the presence of lesions on postoperative MRI. Intraoperative factors such as CPB and RLFP time were not associated with MRI lesions, nor were indirect measures of overall cardiac output such as $\mathrm{SvO}_{2}$, serum lactate, or acid-base status. These data are interesting for 2 reasons. First, they suggest that the postoperative period rather than the intraoperative period may now be the critical period during which neurologic injury occurs or progresses. Second, they suggest that the usual clinical measurements followed in the CICU to assess global cardiac output may not reflect cerebral perfusion, particularly in the early postoperative period, perhaps because of loss of cerebral autoregulation.

The modification of the Norwood procedure to adopt the use of RLFP has been made in many centers to avoid longer periods of DHCA. The association of longer periods of DHCA with impaired neurologic outcome has been well documented, ${ }^{1,7,8,22,23}$ but until recently, DHCA has been believed to be a necessary component of arch reconstruction. RLFP limits the period of cerebral ischemia, improves cerebral oxygenation, and has been shown to be associated with better neurologic outcome in piglets. ${ }^{14}$ It is unknown, however, whether RLFP is associated with better neurologic outcome after the Norwood procedure. Our study demonstrates that ischemic lesions on MRI are no less frequent in patients who underwent surgery with RLFP versus those who underwent surgery with DHCA. ${ }^{12}$ Hoffman and colleagues ${ }^{24}$ have noted that although RLFP provides consistent brain perfusion associated with high $\mathrm{rSO}_{2}$, cerebral desaturation occurs rapidly on removal from CPB. Furthermore, they noted that cerebral $\mathrm{rSO}_{2}$ decreased to much lower levels after $\mathrm{CPB}$ than somatic $\mathrm{rSO}_{2}$ (measured in the splanchnic bed), suggesting that cerebral vascular resistance is higher than somatic resistance in this time period. We noted an identical rapid decrease in cerebral $\mathrm{rSO}_{2}$ in our patients after separation from $\mathrm{CPB}$, which persisted in the early postoperative period.

Animal models of cerebral hypoxia-ischemia have demonstrated an association between low $\mathrm{rSO}_{2}$ and neuronal dysfunction, cell death, and poor neurologic outcome. In a piglet model of graded hypoxia-ischemia to determine thresholds for neurologic injury, brain tissue lactate accumulation began when $\mathrm{rSO}_{2}$ decreased to less than $45 \%$. $^{25}$ Our findings suggest that the $\mathrm{rSO}_{2}$ threshold for neuronal injury is similar in neonates and that maneuvers to improve cerebral perfusion during the postoperative period may lessen the incidence of postoperative ischemia. There are both animal and human data associating low $\mathrm{rSO}_{2}$ and neurologic outcome. ${ }^{26,27}$

The clinical relevance of our MRI findings is unknown. In the preterm neonate, however, MRI findings of PVL have been associated with long-term neurocognitive impairment, including visuospatial and visuomotor abnormalities, attention deficit disorders, and developmental delay. ${ }^{28,29}$ Given the frequency of neurodevelopmental abnormalities in patients with HLHS, it seems likely that these lesions are clinically relevant as well. 


\section{Limitations}

A limitation of this study is that neurodevelopmental evaluation of these children is not yet available. Although an association between MRI findings and neurodevelopmental outcome has been established in preterm infants, this association has not yet been found for infants with congenital heart disease. A second limitation is the timing of the postoperative MRI, which was performed at a median of 9.5 days after surgery. Although the patients were not clinically suitable for transport and MRI scanning until this time, we cannot definitively pinpoint the timing of the ischemia (operative vs postoperative). Third, our patients had just one postoperative MRI scan. In one study, resolution of MRI lesions occurred on later MRI in some patients, ${ }^{12}$ making clinical follow-up even more crucial. Last, we used previous studies in which DHCA was used for the Norwood as a comparison group for our patients rather than a "control" DHCA group within our own institution, so we cannot eliminate the possibility of institutional differences accounting for some of our findings.

\section{Conclusions}

MRI ischemic lesions occur in approximately $25 \%$ of infants with HLHS before surgical palliation. In addition, despite the use of RLFP during the Norwood operation, new or worsened MRI ischemic lesions occurred in $73 \%$ of infants after surgery. Prolonged low postoperative $\mathrm{rSO}_{2}(<45 \%)$ is associated with the development of ischemic lesions.

We are indebted to our nurse coordinators, Tracey VanVliet, RN, Teresa Barnard, RN, and Lois Bogenschutz, RN, for their tireless assistance.

\section{References}

1. Kern JH, Hinton VJ, Nereo NE, Hayes CJ, Gersony WM. Early developmental outcome after the Norwood procedure for hypoplastic left heart syndrome. Pediatrics. 1998;102:1148-52.

2. Goldberg CS, Schwartz EM, Brunberg JA, et al. Neurodevelopmental outcome of patients after the Fontan operation: a comparison between children with hypoplastic left heart syndrome and other functional single ventricle lesions. J Pediatr. 2000;137:646-52.

3. Wernovsky G, Stiles KM, Gauvreau K, et al. Cognitive development after the Fontan operation. Circulation. 2000;102:883-9.

4. Rogers BT, Msall ME, Buck GM, et al. Neurodevelopmental outcome of infants with hypoplastic left heart syndrome. J Pediatr. 1995;126: 496-8.

5. Mahle WT, Clancy RR, Moss EM, Gerdes M, Jobes DR, Wernovsky G. Neurodevelopmental outcome and lifestyle assessment in schoolaged and adolescent children with hypoplastic left heart syndrome. Pediatrics. 2000;105:1082-9.

6. Hickey PR. Neurologic sequelae associated with deep hypothermic circulatory arrest. Ann Thorac Surg. 1998;65:S65-9; discussion S6970, S74-6.

7. Newburger JW, Jonas RA, Wernovsky G, et al. A comparison of the perioperative neurologic effects of hypothermic circulatory arrest versus low-flow cardiopulmonary bypass in infant heart surgery. $N$ Engl J Med. 1993;329:1057-64.

8. Bellinger DC, Jonas RA, Rappaport LA, et al. Developmental and neurologic status of children after heart surgery with hypothermic circulatory arrest or low-flow cardiopulmonary bypass. $N$ Engl J Med. 1995;332:549-55.
9. Forbess JM, Visconti KJ, Bellinger DC, Jonas RA. Neurodevelopmental outcomes in children after the Fontan operation. Circulation. 2001(Suppl I);104:127-32.

10. Wypij D, Newburger JW, Rappaport LA, et al. The effect of duration of deep hypothermic circulatory arrest in infant heart surgery on late neurodevelopment: the Boston Circulatory Arrest Trial. J Thorac Cardiovasc Surg. 2003;126:1397-403.

11. Glauser TA, Rorke LB, Weinberg PM, Clancy RR. Acquired neuropathologic lesions associated with the hypoplastic left heart syndrome. Pediatrics. 1990;85:991-1000.

12. Mahle WT, Tavani F, Zimmerman RA, et al. An MRI study of neurological injury before and after congenital heart surgery. Circulation. 2002(Suppl I);106:109-14.

13. Pigula FA, Nemoto EM, Griffith BP, Siewers RD. Regional low-flow perfusion provides cerebral circulatory support during neonatal aortic arch reconstruction. J Thorac Cardiovasc Surg. 2000;119:331-9.

14. Myung RJ, Petko M, Judkins AR, et al. Regional low-flow perfusion improves neurologic outcome compared with deep hypothermic circulatory arrest in neonatal piglets. J Thorac Cardiovasc Surg. 2004; 127:1051-6; discussion 1056-7.

15. Wernovsky G, Wypij D, Jonas RA, et al. Postoperative course and hemodynamic profile after the arterial switch operation in neonates and infants: a comparison of low-flow cardiopulmonary bypass and circulatory arrest. Circulation. 1995;92:2226-35.

16. Shore S, Nelson DP, Pearl JM, et al. Usefulness of corticosteroid therapy in decreasing epinephrine requirements in critically ill infants with congenital heart disease. Am J Cardiol. 2001;88:591-4.

17. Morris CD, Outcalt J, Menashe VD. Hypoplastic left heart syndrome: natural history in a geographically defined population. Pediatrics. 1990;85:977-83

18. Licht DJ, Wang J, Silvestre DW, et al. Preoperative cerebral blood flow is diminished in neonates with severe congenital heart defects. J Thorac Cardiovasc Surg. 2004;128:841-9.

19. Donofrio MT, Bremer YA, Schieken RM, et al. Autoregulation of cerebral blood flow in fetuses with congenital heart disease: the brain sparing effect. Pediatr Cardiol. 2003;24:436-43.

20. Kaltman JR, Di H, Tian Z, Rychik J. Impact of congenital heart disease on cerebrovascular blood flow dynamics in the fetus. Ultrasound Obstet Gynecol. 2005;25:32-6.

21. Kurth CD, Steven JL, Montenegro LM, et al. Cerebral oxygen saturation before congenital heart surgery. Ann Thorac Surg. 2001; 72:187-92.

22. Jonas RA, Bellinger DC, Rappaport LA, et al. Relation of pH strategy and developmental outcome after hypothermic circulatory arrest. J Thorac Cardiovasc Surg. 1993;106:362-8.

23. Bellinger DC, Wypij D, duPlessis AJ, et al. Neurodevelopmental status at eight years in children with dextro-transposition of the great arteries: the Boston Circulatory Arrest Trial. J Thorac Cardiovasc Surg. 2003; 126:1385-96.

24. Hoffman GM, Ghanayem NS, Stuth EA, Berens RJ, Tweddell JS. NIRS-derived somatic and cerebral saturation difference provides noninvasive real time hemodynamic assessment of cardiogenic shock and anaerobic metabolism (Abstract). Anesthesiology. 2004;101:A1448.

25. Kurth CD, Levy WJ, McCann J. Near-infrared spectroscopy cerebral oxygen saturation thresholds for hypoxia-ischemia in piglets. J Cereb Blood Flow Metab. 2002;22:335-41.

26. Sakamoto T, Hatsuoka S, Stock UA, et al. Prediction of safe duration of hypothermic circulatory arrest by near-infrared spectroscopy. J Thorac Cardiovasc Surg. 2001;122:339-50.

27. Austin EH III, Edmonds HL Jr, Auden SM, et al. Benefit of neurophysiologic monitoring for pediatric cardiac surgery. $J$ Thorac Cardiovasc Surg. 1997;114:707-15, 717; discussion 715-6.

28. Skranes JS, Vik T, Nilsen G, et al. Cerebral magnetic resonance imaging (MRI) and mental and motor function of very low birth weight infants at one year of corrected age. Neuropediatrics. 1993;24: 256-62.

29. Olsen P, Vainionpaa L, Paakko E, Korkman M, Pyhtinen J, Jarvelin MR. Psychological findings in preterm children related to neurologic status and magnetic resonance imaging. Pediatrics. 1998;102: 329-36. 